\title{
Vertical Transmission of HIV and Toxoplasma by Reactivation in a Chronically Infected Woman
}

\begin{abstract}
Regina Célia de Souza Campos Fernandes ${ }^{1,2}$, Vanessa Perez Vasconcellos ${ }^{1}$, Luciana Cordeiro de Araújo ${ }^{3}$ and Enrique Medina-Acosta $^{4}$ ${ }^{1}$ Municipal Program for the Surveillance of Sexually Transmitted Diseases and AIDS of Campos dos Goytacazes; ${ }^{2}$ School of Medicine of Campos; ${ }^{3}$ Guarus Municipal General Hospital; ${ }^{4}$ State University of the North Fluminense Darcy Ribeiro; Campos dos Goytacazes, RJ, Brazil
\end{abstract}

Prevention of mother-to-child transmission of HIV and Toxoplasma dual infections in the immunocompromised patient remains a healthcare challenge. We report a case of congenital toxoplasmosis resulting from reactivation of latent infection in a severely immunodepressed HIV-infected pregnant woman, who had poor adherence to therapy; this case illustrates the difficulties encountered in management of such a rare condition.

Key-Words: Congenital toxoplasmosis, reactivation, HIV infection.

In immunocompromised patients, Toxoplasma gondii infection causes severe manifestations, including splenomegaly, chorioretinitis, pneumonitis, encephalitis, multisystem organ failure, and even death [1]. In patients infected with human immunodeficiency virus (HIV), more than $95 \%$ of Toxoplasma encephalitis cases involve reactivation of a latent infection [2]. Contrary to the situation in adults, toxoplasmosis of the central nervous system is not a common opportunistic infection in children infected with HIV. Rather, severe congenital toxoplasmosis seems to be more frequent among such children [3]. The absolute risk and clinical sequela of concurrent congenital infections with HIV and Toxoplasma are unknown. However, there seems to be a low general risk of maternal-fetal transmission of Toxoplasma infection from HIV-infected women, even when the CD4 lymphocyte count in the mother is very low $(<200$ cells $/ \mu \mathrm{L})$. This is indicated by the low incidence $(0.95 \%$ in the study by Biederman et al. [4]; $0.72 \%$ in the study by Minkoff et al., [5] and none in the study by the European Collaborative Study and Research Network on Congenital Toxoplasmosis [6]) of congenital toxoplasmosis reported in children born to HIV-infected women.

Given the increasing occurrence of HIV infection among women, association of latent infection with Toxoplasma and HIV infection should receive special attention. We report a case of congenital toxoplasmosis from reactivation of maternal infection due to severe immunodepression related to HIV infection, including the difficulties in management of both diseases in the affected infant.

\section{Case Report}

A 27-year-old HIV-infected pregnant woman sought antenatal care at the Municipal Program for the Surveillance of Sexually Transmitted Diseases and AIDS of Campos dos Goytacazes, State of Rio de Janeiro, in October 2005, at eight weeks gestation. The woman had her HIV status confirmed in 1999, admitted a history of poor adherence to antiretroviral therapy and

Received on 6 October 2008; revised 20 January 2009.

Address for correspondence: Dr. Regina Célia de Souza Campos Fernandes. Rua Rafael Danuncio Damiano 277, Campos dos Goytacazes, Rio de Janeiro, Brazil. Zip code: 28013-035; Phone/Fax: +55 2227266758. E-mail: reg.fernandes@bol.com.br.

The Brazilian Journal of Infectious Diseases

2009;13(1):70-71. (C) 2009 by The Brazilian Journal of Infectious Diseases and Contexto Publishing. All rights reserved. had lost a baby from HIV infection in January 2001. At 20 weeks gestation, her viral load was 45,600 copies $/ \mathrm{mL}(\log 4.65)$ and her CD4 lymphocyte cell count was 53/ $\mu \mathrm{L}$ (4.4\%). Serology: hepatitis C (negative); HBsAg (negative); anti-HBc (negative); rubella: IgG positive(35.7 IU/mL), IgM(negative); VDRL(negative); Toxoplasma: IgG positive (166.2 IU $/ \mathrm{mL}$; reactive $\geq 3 \mathrm{IU} / \mathrm{mL}$ ), IgM(negative). At 24 weeks gestation, a second anti-Toxoplasma serology was positive for IgG $(400 \mathrm{IU} / \mathrm{mL})$ and negative for IgM. After diagnosis of pregnancy, treatment with Efavirenz was discontinued, and she was treated with Zidovudine, Lamivudine, and Nelfinavir, always with poor adherence. The women did not receive prophylactic treatment with trimethoprim/sulfamethoxazole. Her last antenatal examination was at 33 weeks gestation. At 35 weeks gestation, the mother had convulsions, followed by decreased conscience, hemiparesis, and hospitalization. Delivery occurred at 37 weeks gestation, by cesarean section. At delivery, toxoplasmic encephalitis was suspected, based on changes in cognitive status, focal neurological deficit, positive $\mathrm{IgG}$ for Toxoplasma and advanced immunosuppression, with fatal outcome for the mother six days later.

She gave birth to a 2,545 g female infant, length $46 \mathrm{~cm}$, head circumference $32 \mathrm{~cm}$, with APGAR scores $7 / 9$ and normal physical examination. White blood cell count at birth was 15,800 (48\% polymorphonuclear leukocytes, $1 \%$ band forms, $49 \%$ lymphocytes and $1 \%$ monocytes); platelet count was 207,000 / $\mu \mathrm{L}$. Hemoglobin: $14.5 \mathrm{~g} / \mathrm{dL}$; hematocrit: $42.4 \%$; erythroblasts: $65 \%$. anti-Toxoplasma $\operatorname{IgG}(108 \mathrm{IU} / \mathrm{mL})$ and $\operatorname{IgM}(7.97 \mathrm{IU} / \mathrm{mL}$; reactive $\geq 0.55 \mathrm{IU} / \mathrm{mL}$ ). Ultrasound of the head: intracranial hemorrhage grade one. Skull X-ray: intracranial dispersed calcifications. Fundoscopic examination was normal. Clinical Course: At age five days, therapy with oral pyrimethamine $(1 \mathrm{mg} / \mathrm{kg} /$ day $)$, sulfadiazine $(100 \mathrm{mg} / \mathrm{kg} /$ day), plus supplemental folinic acid was started and treated during 12 months; she was treated during 12 months. Trimethoprim-sulfamethoxazole for Pneumocystis pneumonia prophylaxis was not prescribed because of a potential increase in toxicity. Zidovudine was prescribed for six weeks to prevent vertical transmission of HIV. At two months of age, infection by HIV was confirmed; viral load was 1,200,000 copies/ $\mathrm{mL}$ and $\mathrm{CD} 4$ was $27.2 \%(1,378$ cells $/ \mu \mathrm{L})$. Antiretroviral drugs (stavudine, lamivudine, and lopinavir/ritonavir) were started due to failure to thrive and multiple infections at six months of age. Twenty days after treatment, viral load was 11,400 copies $/ \mathrm{mL}$ and CD4 was $30 \%$, coinciding with clinical recovery. At age 11 months, anti-Toxoplasma IgG was $1,070.7 \mathrm{IU} / \mathrm{mL}$ and IgM was $0.86 \mathrm{IU} / \mathrm{mL}$. When this paper was written, the child was two 
years old and presented with neurodevelopment delay, right hemiparesis, strabismus, and bilateral visual impairment due to chorioretinitis.

\section{Discussion}

Children born to HIV-infected women may be at higher risk of vertical transmission of Toxoplasma infection in endemic areas. In our setting, the northern region of the state of Rio the Janeiro, Brazil, anti-Toxoplasma seroprevalence has been reported to increase significantly with age, mainly in the lower socioeconomic strata, from $39.7 \%$ (age range 0 to 9 years-old) to $83.5 \%$ (age range 30 to 39 years-old) [7]. Our case illustrates the possibility of congenital toxoplasmosis by reactivation in a pregnant woman infected with both HIV and Toxoplasma gondii. The woman had severe immunodepression, anti-Toxoplasma IgG (positive) and $\operatorname{IgM}$ (negative) serology at the fifth and sixth months of pregnancy and most likely developed Toxoplasma encephalitis near delivery time, causing her death six days after. Her baby was born with unmarked clinical signs, as expected in cases that fetal infection occurred near the end of pregnancy. X-ray of the skull revealed calcifications. Chorioretinitis was not detected. The infant was positive for both anti-Toxoplasma IgG, most likely reflecting maternal origin from transplacental passage, and $\operatorname{IgM}$, of fetal origin, produced in response to infection. At two months of age, HIV infection was confirmed. Antiretroviral therapy was started at age five months, because of failure to thrive, compromised development, difficulty to control oral candidiasis, repeated respiratory infections and esophagitis due to cytomegalovirus. The Brazilian work group on HIV infection in children does not recommend treatment immediately after confirmation of HIV infection during the first year of life, and only if clinical manifestations or immunosuppression (CD4 count $<25 \%$ ) appear. We followed this recommendation. Adhesion to the two schemes of treatment and periodical evaluation for bone marrow toxicity were reinforced.

As pointed by Remington [8], HIV and Toxoplasma duallyinfected babies do not have clinical signals of either infection at birth. Many of them develop severe manifestations of disseminated infection only weeks or months later. The recommendations are for specific therapy to continue for one year, and for secondary prophylaxis to follow particular guidelines. In Brazil, the recommendation is to maintain therapy until CD4 count is $>15 \%$ in two evaluations. At age nine months, the child's serology demonstrated a normal schedule of evolution, with decreased IgM and elevation of $\mathrm{IgG}$, demonstrating her ability for antibody production, probably associated with treatment and control of HIV infection.

Our interpretation of the sequela in this child was as follows: hemiparesis and neurodevelopment delay appeared to be consequences of progressive encephalopathy due to HIV [9] and may have been propitiated by the introduction of antiretrovirals only at age six months. Strabismus and visual impairment were compatible with ocular lesions due to Toxoplasma, despite specific treatment instituted in the first days of life and maintained during a year. Besides the contribution of immunosuppression due to HIV infection, it is important to consider the interference of the peculiarities of Toxoplasma parasite infection in our setting [10].

This case highlights the importance of timing and type of prenatal treatment for toxoplasmosis, and follow-up of maternal HIV disease during pregnancy. Immunodepression, even when discrete, may allow transmission of latent maternal infections to the newborn [11], which could be prevented by adequate treatment. Immunocompromised pregnant women should be screened for toxoplasmosis, cytomegalovirus and other agents at various times during pregnancy. There are successful examples of intervention in this setting, preserving the health of the mother and avoiding infection of the fetus [12]. Under these conditions, prophylaxis or therapy is required. Clearly, adhesion to therapy should have been more efficiently reinforced by the multidisciplinary group in this case. Finally, all babies resulting from these pregnancies must also be submitted to screening at birth and completely investigated. This strategy would contribute towards immediate use of specific therapies, with better prognosis and lower frequencies of sequela.

\section{Acknowledgements}

The authors thank the child and mother who participated in this study. This study was financed by the Municipal Health Department of the city of Campos dos Goytacazes, the National Program for STD/AIDS and by a grant from Ministry of Health/ UNESCO to E.M-A.

\section{References}

1. Montoya J.G., Liesenfeld O. Toxoplasmosis. Lancet 2004;363:1965-76.

2. Luft B.J., Chua A. Central Nervous System Toxoplasmosis in HIV Pathogenesis, Diagnosis, and Therapy. Curr Infect Dis Rep 2000; $2: 358-62$.

3. Abrams E.J. Opportunistic infections and other clinical manifestations of HIV disease in children. Pediatr Clin North Am 2000;47:79-108.

4. Biedermann K., Flepp M., Fierz W., et al. Pregnancy, immunosuppression and reactivation of latent toxoplasmosis. J Perinat Med 1995;23:191-203.

5. Minkoff H., Remington J.S., Holman S., et al. Vertical transmission of toxoplasma by human immunodeficiency virus-infected women. Am J Obstet Gynecol 1997;176:555-9.

6. Minkoff H., Remington J.S., Holman S., et al. Low incidence of congenital toxoplasmosis in children born to women infected with human immunodeficiency virus. European Collaborative Study and Research Network on Congenital Toxoplasmosis. Eur J Obstet Gynecol Reprod Biol 1996;68:93-96.

7. Bahia-Oliveira L.M., Jones J.L., Azevedo-Silva J., et al. Highly endemic, waterborne toxoplasmosis in north Rio de Janeiro state, Brazil. Emerg Infect Dis 2003;9:55-62.

8. Remington J.S. Toxoplasmosis. In: Remington J.S., Klein J., Baker C., Wilson C., eds. Infectious diseases of the fetus and the newborn infant. 5th ed. Philadelphia: Elsevier Saunders; 2001:205-346.

9. Van Rie A., Harrington P.R., Dow A., Robertson K. Neurologic and neurodevelopmental manifestations of pediatric HIV/AIDS: a global perspective. Eur J Paediatr Neurol 2007;11:1-9.

10. Thiebaut R., Leproust S., Chene G., Gilbert R. Effectiveness of prenatal treatment for congenital toxoplasmosis: a meta-analysis of individual patients' data. Lancet 2007;369:115-22.

11. Bachmeyer C., Mouchnino G., Thulliez P., Blum L. Congenital toxoplasmosis from an HIV-infected woman as a result of reactivation. J Infect 2006;52:e55-7.

12. Nogueira S.A., Guedes A.L., Machado E.S., et al. Toxoplasmic encephalitis in an HIV infected pregnant woman: successful outcome for both mother and child. Braz J Infect Dis 2002;6:201-5. 